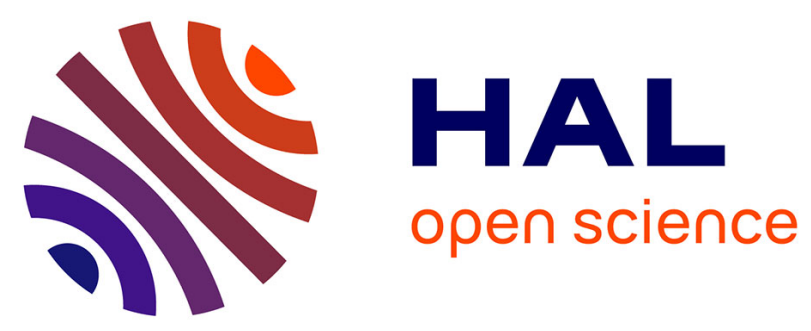

\title{
Effect of sterilisation and storage conditions on the migration of bisphenol A from tinplate cans of the Lebanese market
}

Sara Noureddine El Moussawi, Reine Karam, Mathieu Cladière, Hanna

Chébib, Rosette Ouaini, Valérie Camel

\section{To cite this version:}

Sara Noureddine El Moussawi, Reine Karam, Mathieu Cladière, Hanna Chébib, Rosette Ouaini, et al.. Effect of sterilisation and storage conditions on the migration of bisphenol A from tinplate cans of the Lebanese market. Food additives \& contaminants. Part A. Chemistry, analysis, control, exposure \& risk assessment, 2018, 35 (2), pp.377-386. 10.1080/19440049.2017.1395521 . hal-01766696

\section{HAL Id: hal-01766696 \\ https://hal.science/hal-01766696}

Submitted on 26 May 2020

HAL is a multi-disciplinary open access archive for the deposit and dissemination of scientific research documents, whether they are published or not. The documents may come from teaching and research institutions in France or abroad, or from public or private research centers.
L'archive ouverte pluridisciplinaire HAL, est destinée au dépôt et à la diffusion de documents scientifiques de niveau recherche, publiés ou non, émanant des établissements d'enseignement et de recherche français ou étrangers, des laboratoires publics ou privés. 


\section{Effect of sterilization and storage conditions on the migration of bisphenol A from tinplate cans of the Lebanese market}

Sara Noureddine ElMoussawi ${ }^{1,2}$, Reine Karam ${ }^{1,2}$, Mathieu Cladière ${ }^{1}$, Hanna Chébib $^{2}$, Rosette Ouaini ${ }^{2}$, Valérie Camel ${ }^{1 *}$

${ }^{1}$ UMR Ingénierie Procédés Aliments, AgroParisTech, Inra, Université Paris-Saclay, 91300 Massy, France

${ }^{2}$ ER004 Lebanese Food Packaging, Faculty of Sciences II, Lebanese University, 90656 Jdeideth El Matn, Fanar, Lebanon

* Corresponding author: valerie.camel@agroparistech.fr

\section{Highlights}

- First report of BPA detection in tinplate cans manufactured in Lebanon

- BPA levels in aqueous simulant from sterilized cans ranged between 80 and $150 \mu \mathrm{g} / \mathrm{kg}$

- Sterilization process accelerated BPA migration (around $10.5 \mu \mathrm{g} / \mathrm{dm}^{2}$ ) 


\section{Effect of sterilization and storage conditions on the migration of bisphenol A from tinplate cans of the Lebanese market}

The use of bisphenol A (BPA) in lacquer coating of food cans has been restricted by different authorities in many countries, such as in Europe. However, such regulation does not exist in many countries as Lebanon. Due to the lack of data on the quality of Lebanese can production, this study investigates the migration of BPA from two types of tinplate cans manufactured in Lebanon, before and after sterilization. Cans were analyzed under different storage conditions (time and temperature) and filled with an aqueous simulant. The determination of BPA was carried out using UPLC with fluorescence detection, and further confirmed by MS detection. After sterilization BPA levels drastically increased from an average of 0.15 to $109 \mu \mathrm{g} / \mathrm{kg}$, giving a BPA migration around $10.5 \mu \mathrm{g} / \mathrm{dm}^{2}$ for both types of cans. Storage temperature and time had no significant influence on BPA levels in sterilized cans ( $p$-value $>0.05$ ); on the opposite, these factors significantly affected BPA levels in non-sterilized cans.

Keywords: bisphenol A, tinplate cans, aqueous food simulant, sterilization, storage conditions. 


\section{Introduction}

Bisphenol A (BPA) or 2,2-bis(4-hydroxyphenyl)propane is a chemical used as a monomer in the manufacturing of resins and plastics in order to prevent direct contact between the metal wall of the can and the food/ beverage as well as to protect the inside wall of the can from rusting and corrosion. As BPA was discovered to have estrogenic activity (Rubin 2011), it gained a great concern in the past few years since BPA free monomers can migrate in residual amounts into food or beverages once packed in materials containing the substance, so that BPA may further interrupt our endocrine system once ingested (Haffner et al. 2010; Oldring et al. 2014). Moreover, many studies have reported possible association between BPA ingestion and various health hazards such as heart disease including heart attacks, coronary heart disease, and angina as well as decreased sexual desire, erectile, and ejaculatory problems (Li et al. 2010; Melzer et al. 2010). Due to health concern, the European Commission has set the specific migration limit of $600 \mu \mathrm{g} / \mathrm{kg}$ for BPA in plastic materials and articles intended to come in contact with foodstuffs (EU Regulation 10/2011) (European Union 2011). Very recently, on January 2015, France even banned the use of BPA in all food contact materials (République française 2012). Still in 2015, the EFSA (European Food Safety Authority) issued risk assessments for consumers and revised its BPA temporary Tolerable Daily Intake (t-TDI) to 4 instead of $50 \mu \mathrm{g} / \mathrm{kg}$ bw per day (Efsa 2015). Upon assessment of external exposure to BPA from all sources, diet was found the main source for all population groups, specifically due to canned food (Efsa 2015). Even if dietary exposure is not at risk according to the EFSA, conclusions from other agencies widely differed. In particular, the French Anses and the Danish Food Institute still consider that risk associated with the presence of BPA in diet, especially due to canned food, may not be excluded (Anses 2015; DTU Food 2015). Hence, the EFSA continues to work on this topic in 2017, especially by reviewing all the scientific evidence published after 2012 and relevant for BPA hazard characterization (including immunotoxicity) (Efsa 2016).

Many studies showed migration of BPA from packaging into food. Most of them focused on epoxy lining in tinplate cans which is expected to present the highest possible migration among other food packaging. According to a study on Belgian market, BPA ranged between 1 and $40.3 \mu \mathrm{g} / \mathrm{kg}$ in canned food (Geens et al. 2010). Similar values (average of $1.1 \mu \mathrm{g} / \mathrm{kg}$ ) were reported in baby food packed in glass jars with metal lids coated with epoxy lining present in the Canadian market (Cao et al. 2009b). Up to $730 \mu \mathrm{g} / \mathrm{kg}$ has been even reported in highly consumed canned food on the U.S. market (Noonan et al. 2011). The migration of BPA in canned food in nine cities of China was reported to be higher than in food preserved with other types of packaging, with an average BPA concentration around $20 \mu \mathrm{g} / \mathrm{kg}$ (Liao et al. 2014). This issue was highly discussed in many other countries, but to our best knowledge there is a lack of data in Lebanon, where tinplate cans are manufactured and used in the food industry. In addition, since Lebanese cuisine is highly appreciated regionally and recognized globally, considerable amounts of canned food are being exported annually to Europe, the US, and neighboring countries (according to the Lebanese customs on national trades, the average of annual exportation over the 2013-2016 period is about 29,000 tons of canned food) (Lebanese Customs 2017). Consequently, it is of prime importance to insure the validity of this production sector.

Therefore, the aim of the present work was to study the effect of storage time and temperature as well as the sterilization process on the migration of BPA into aqueous 
food simulants packed in two different types of tinplate cans manufactured in Lebanon and dedicated to non-acidic aqueous foods. The experiments were planned using a full factorial design and the significance of the effect of each parameter was established using the p-value approach. BPA was quantified by UPLC/Fluorescence and confirmed using UPLC/MS. Our results give a preview of BPA levels that shall migrate from Lebanese tinplate cans into food, which is of concern with respect to exposure assessment of both the Lebanese population (for which there is a lack of data until now, despite its high consumption of canned food) and the European population since Lebanese canned foods are widely exported to Europe.

\section{Materials and method}

\section{Reagents}

Bisphenol A (BPA, 99.9\% purity, $228.29 \mathrm{~g} / \mathrm{mol}$ ) was purchased from Fluka Analytical (France). Ethanol, methanol and acetonitrile (HPLC-plus gradient grade) were obtained from Carlo Erba (France). Ultrapure, Milli-Q, water $\left(18.2 \mathrm{M} \Omega / \mathrm{cm}\right.$ at $\left.25^{\circ} \mathrm{C}\right)$ was produced by an Integral 3 water purification system from Millipore ${ }^{\circledR}$.

\section{Sample collection}

Tinplate cans were manufactured in one of the biggest canning factories in Lebanon. According to the manufacturer, the raw tinplate sheets were imported from France while the liquid epoxy coating was coming from Italy. In the plant, the tinplate sheets had been coated with wet epoxy resins, cross linked with phenolic binders, and cured in an oven for $20 \mathrm{~min}$ at $200^{\circ} \mathrm{C}$. The sheets were then cut and shaped into cylinders by electric welding. Additional epoxy-phenolic powder was applied on the welding side and subjected to another curing. Two types of cans were collected; the cans of each type were from the same batch, while both types of cans were produced within the same period. Cans of the first type were intended for packing vegetables (fava beans, okra) and fruits; the epoxy-phenolic resin was pigmented with titanium oxide to give a white appearance (18 cans: $10.1 \mathrm{~cm}$ height, $7.3 \mathrm{~cm}$ diameter, $400 \mathrm{~g}$ capacity, food contact surface area of $3.15 \mathrm{dm}^{2}$ ). The cans of the second category were of smaller size and used to pack processed meat; the epoxy-phenolic resin was pigmented with carbon black, giving a gray appearance, and covered with wax layer to facilitate meat sliding from the can (17 cans: $5.3 \mathrm{~cm}$ height, $7.3 \mathrm{~cm}$ diameter, and $140 \mathrm{~g}$ capacity, food contact surface area of $2.05 \mathrm{dm}^{2}$ ). Large and small cans are referred to as (L) and (S) respectively. All cans were three-piece cans with easy open ends.

\section{Analytical instruments and conditions}

\section{UPLC/Fluorescence}

A UPLC Agilent ${ }^{\circledR} 1260$ Infinity Series system equipped with a multi-wave fluorescence detector was used for quantification of BPA. The system was accompanied with an autosampler; the injected volume was set at $20 \mu 1$.Pentafluorophenyl grafted octadecyl silica column (C18-PFP, 150*2.1 mm ID, $2 \mu \mathrm{m}$ particle size, $\mathrm{ACE}^{\circledR}$ ) was used for the separation of targeted compound at constant temperature of $25^{\circ} \mathrm{C}$. The mobile phase, consisting of water (A) and acetonitrile (B), was pumped at a flow rate of $0.4 \mathrm{ml} / \mathrm{min}$ and the following binary gradient was applied: 0 to $5 \min -30 \% \mathrm{~B}, 8$ to $12 \mathrm{~min}-40 \%$ 
B, 14 to $17 \mathrm{~min}-100 \% \mathrm{~B}$, and 17 to $20 \mathrm{~min}$ - back to $30 \% \mathrm{~B}$. For detection of BPA, excitation and emission wavelengths were set at $230 \mathrm{~nm}$ and $316 \mathrm{~nm}$ respectively. Data were exported using ChemStation (Agilent, LC1260).

\section{$U P L C / M S$}

The confirmation of BPA peak was carried out on a UPLC XEVO G2S ${ }^{\circledR}$ (Waters, France) system equipped with quantitative time-of-flight mass spectrometry detector (QuanTof $^{\text {TM }}$ MS) incorporating StepWave ${ }^{\mathrm{TM}}$ ion optics, using the same chromatographic column as previously. Mass spectrometer was equipped with electrospray ionization mode switching (ESCi) source, operating in negative mode (ESI ${ }^{-}$ ). The mobile phase was composed of water plus $10 \mathrm{mM}$ of ammonium formate (A) and methanol (B). The flow rate of mobile phase was $0.3 \mathrm{ml} / \mathrm{min}$ with gradient: 0 to $5 \mathrm{~min}$ $50 \% \mathrm{~B}, 8$ to $12 \mathrm{~min}-60 \% \mathrm{~B}, 14$ to $17 \mathrm{~min}-100 \% \mathrm{~B}$ and 17 to $20 \mathrm{~min}$ - back to $50 \% \mathrm{~B}$. The injection was automatic with $10 \mu \mathrm{L}$ injection volume. For each analysis a full scan spectrum (mass range 190-600 $\mathrm{m} / \mathrm{z}$, scan time $0.5 \mathrm{~s}$ ) was acquired for identification purposes under the following conditions: capillary voltage $1 \mathrm{kV}$; sample cone and source offset 65 and 45 a.u, respectively. Desolvation and cone gas flow were respectively 600 and $20 \mathrm{~L} / \mathrm{min}$, while desolvation and source temperature were set at 500 and $130^{\circ} \mathrm{C}$. Data acquisition was performed on MassLynx ${ }^{\mathrm{TM}}$ version 4.

\section{Sample preparation}

Since the majority of canned foodstuffs concerned by the studied tinplate cans here are aqueous (estimated range $60-95 \%$ of water / net weight), we initially chose $10 \%$ ethanol as food simulant according to EU Regulation 10/2011(European Union 2011). However, most of the cans containing $10 \%$ ethanol failed to support sterilization. Since BPA levels in the few cans filled with $10 \%$ ethanol that passed the sterilization process were similar to the levels found using water for the same type of cans, water was finally retained as the simulant in all our experiments. Other authors have also used water as simulant since it was recommended in previous European regulation. In the case of BPA, water could be more appropriate than $10 \%$ ethanol since the latter was reported to overestimate BPA migration as compared to foods (Goodson et al. 2004).

(L) and (S) cans were filled with 350 and $175 \mathrm{ml}$ of water respectively, leading to 111 and $85 \mathrm{~mL} / \mathrm{dm}^{2}$ as values of the ratio between simulant volume and food contact surface area for (L) and (S) cans respectively. Cans were manually sealed and sterilized in two different batches (15 cans per batch, randomly distributed in the pilot) in an ACB autoclave for $30 \mathrm{~min}$ at $121^{\circ} \mathrm{C}$. Some cans were sealed without sterilization in order to investigate the effect of sterilization. Sterilized and non-sterilized samples are referred to as (HP) and (NHP) respectively (HP meaning heat process).

Aliquots from (HP) samples were diluted ten times with $30 \%$ acetonitrile prior to UPLC analysis due to the presence of high concentrations of BPA after sterilization. On the other hand, (NHP) samples were found to have non-detectable levels of BPA when directly analyzed; therefore, the latter required pre-concentration by SPE before analysis. For that purpose, Supelco-HLB $(60 \mathrm{mg} / 3 \mathrm{~mL})$ cartridges (SPE manual Visiprep $^{\mathrm{TM}}$ system used) were conditioned and equilibrated with $5 \mathrm{~mL}$ of methanol followed by $5 \mathrm{~mL}$ of ultrapure water. After percolation of the sample $(10 \mathrm{~mL})$ onto the SPE cartridge and washing with $5 \mathrm{~mL}$ of water/methanol 95:5 (v/v), each extract was eluted with $5 \mathrm{~mL}$ of methanol. After subsequent evaporation to dryness under nitrogen flow at $40^{\circ} \mathrm{C}$, residues were recovered with $1 \mathrm{~mL}$ water/acetonitrile $70 / 30(\mathrm{v} / \mathrm{v})$ and analyzed. Background contamination arising from lab ware was avoided by rising 
glassware with methanol before use. Blank samples were also performed to investigate possible BPA contamination coming from the SPE cartridges or the simulant.

\section{Storage conditions}

Heat processing as well as storage time and temperature are expected to be the primary influencing parameters on the migration of BPA into food simulant (Munguia-Lopez et al. 2001). In this study, (HP) and (NHP) cans filled with the simulant were stored from one to fifteen days at $5,22.5$ and $40^{\circ} \mathrm{C}$. Since most of studies investigated the short term migration of BPA, we tested the effect of long term storage of cans at room temperature through accelerated aging under $60^{\circ} \mathrm{C}$ for 10 days (equivalent to 6 months at room temperature) according to EU Regulation 10/2011 (European Union 2011).

\section{Procedure used in the experimental design}

Plackett-Burman designs constitute a variation of saturated fractional designs, allowing the evaluation of the weight of each factor on the outcomes as well as the effect of interaction between these factors (Jalbani et al. 2006). For evaluating the effect of two factors (storage time and temperature for HP samples) as well as their possible interactions, a Central Composite Design (CCD) with ten experiments has been built. This full factorial design $3^{2}$ contains center points in addition to one repetition of one experiment. Three levels per factor were chosen as low (-), middle $(0)$ and high $(+)$ levels representing $1,8,15$ days of storage time and $5,22.5,40^{\circ} \mathrm{C}$ of storage temperature, respectively. The CCD matrix was performed on both (L) and (S) cans. All the experimental data were processed using JMP 10 Design of Experiments and Microsoft Excel 2007. In order to establish statistical differences between the means of BPA concentration in food stimulants stored under different conditions, a multi-factor analysis of variance, with least significant difference (LSD) at significance level 0.05 , was calculated by Fisher's test.

\section{Results and discussion}

\section{Quality assurance}

\section{Analytical performance}

Quantification was performed with external calibration of integrated peak areas of ten points in the range between 0.25 and $40 \mu \mathrm{g} / \mathrm{L}$ by diluting the stock solution with $70: 30$ $(\mathrm{v} / \mathrm{v})$ of water/ acetonitrile mixture. Linearity with $\mathrm{R}^{2}$ value 0.999 was observed for BPA's calibration over the range $0.25-40 \mu \mathrm{g} / \mathrm{L}$ (Table 1). Precision under repeatability and reproducibility conditions were also estimated from standard deviation of five calibration curves. The deviation between different calibration curves was $<5 \%$. Intraday and inter-day precision of instrument were determined through injecting three different standards $(0.1,20$ and $40 \mu \mathrm{g} / \mathrm{L})$ and one (HP) sample within the same day or on three different days $(n=5)$, respectively. The instrumental within-day repeatability and between-day reproducibility are acceptable $(<5$ and $10 \%$ respectively) as indicated in Table 1. 
Table 1: Method performance and accuracy.

\begin{tabular}{|c|c|c|c|c|}
\hline & $\begin{array}{l}\text { BPA } \\
\text { concentration } \\
(\mu \mathrm{g} / \mathrm{L})\end{array}$ & $\begin{array}{l}\text { RSD } \\
(\%)\end{array}$ & $\begin{array}{l}\text { Calibration } \\
\text { equation }\end{array}$ & $\begin{array}{l}\text { Regression } \\
\text { coefficient }^{b}\end{array}$ \\
\hline Linearity & $0.25-40$ & & $\begin{array}{l}y=18.25( \pm 1.5) x- \\
4.83( \pm 3.5)\end{array}$ & $\mathrm{R}^{2}=0.999$ \\
\hline $\begin{array}{l}\mathrm{LOD}^{\mathrm{a}^{\prime}} \\
\mathrm{MDL}^{\prime} \\
\mathrm{LOQ}^{\mathrm{a}^{\prime}} \\
\mathrm{MQL}\end{array}$ & $\begin{array}{l}0.1 \\
0.01 \\
0.25 \\
0.025\end{array}$ & & & \\
\hline $\begin{array}{l}\text { Within-day } \\
\text { repeatability }\end{array}$ & $\begin{array}{l}0.1 \\
20 \\
40 \\
\text { (HP) sample }\end{array}$ & $\begin{array}{l}4.39 \\
0.33 \\
0.24 \\
0.51\end{array}$ & & \\
\hline $\begin{array}{l}\text { Between-day } \\
\text { reproducibility e }\end{array}$ & $\begin{array}{l}20 \\
40\end{array}$ & $\begin{array}{l}6.52 \\
9.47\end{array}$ & & \\
\hline $\begin{array}{l}\text { Repeatability } \\
\text { between cans }{ }^{f}\end{array}$ & 87 & 9.4 & & \\
\hline Recovery ${ }^{\mathrm{g}, \mathrm{h}}$ & $\begin{array}{l}0.08 \\
1\end{array}$ & \multicolumn{2}{|c|}{$\begin{array}{l}110 \pm 1.5 \% \\
98 \pm 2.6 \%\end{array}$} & \\
\hline $\begin{array}{l}{ }^{\mathrm{a}} \mathrm{n}=10 ;{ }^{\mathrm{b}} \text { mea } \\
{ }^{\mathrm{c}} \mathrm{n}=5 \text { injection } \\
{ }^{\mathrm{d}}(\mathrm{HP}) \text { sample } \\
{ }^{\mathrm{e}} \mathrm{n}=5 \text { injection } \\
{ }^{\mathrm{f}} 12 \text { cans }-3 \mathrm{~d} \\
{ }^{\mathrm{g}}{ }_{n=3} \\
{ }^{\mathrm{h}} \text { mean recove }\end{array}$ & $\begin{array}{l}\text { gression coeffic } \\
\text { f one solution pe } \\
\text { ound } 100 \mu \mathrm{g} / \mathrm{L} \text {, } \\
\text { er day over } 3 \mathrm{da} \\
\text { ent batches } \\
\text { RSD }\end{array}$ & $\begin{array}{l}(n=5) \\
\text { el } \\
\text { ed } 10 t \\
\text { fone so }\end{array}$ & $\begin{array}{l}\text { hes before injection } \\
\text { ation per level }\end{array}$ & \\
\hline
\end{tabular}

\section{Detection and quantification limits}

Instrumental LOD and LOQ were determined by preparing 5 replicates of 10 calibration standards, ranging between 0.1 and $1 \mu \mathrm{g} / \mathrm{L}$, each replicate being analyzed twice. The repeatability (expressed as \% RSD) at each level was calculated based on these 10 values per level. LOD and LOQ were then estimated as the BPA concentrations leading to RSD of 30 and $10 \%$, respectively. LOQ was then experimentally checked when assessing the calibration curve. Method detection and quantification limits (MDL and MQL) were estimated by dividing respectively LOD and LOQ by the method preconcentration factor $\left(f_{c}=10\right)$. The results are shown in Table 1 .

In order to investigate method selectivity and the absence of any interferences of BPA coming from the analytical method, 10 sample blanks (i.e. ultrapure water) were allowed to run through SPE cartridges and through the rest of the method. After the analysis of these sample blanks on UPLC system, no interferences appeared to elute at the retention time of BPA. 


\section{BPA pre-concentration recovery}

Two levels of BPA $(0.08$ and $1 \mu \mathrm{g} / \mathrm{L})$ were fortified into water samples of $10 \mathrm{~mL}(\mathrm{n}=3)$ and SPE extraction was conducted under the same conditions as previously detailed for (NHP) samples. The mean recovery ranged between $98 \pm 2.6 \%$ and $110 \pm 1.5 \%$ as indicated in Table 1.

\section{Sterilization repeatability}

Repeatability in sterilization between different batches as well as the homogenous distribution of temperature in the pilot was tested. Fifteen cans of (L) type, each containing $350 \mathrm{~mL}$ of water, were sterilized in three different batches. The samples were distributed randomly in the autoclave. Three cans (one per batch) were dedicated to temperature controlling samples in order to follow the temperature variation inside the cans during the sterilization duration, and the other 12 cans were used for testing between-batch repeatability of BPA migration during sterilization. The process was highly repeatable with a variation coefficient not exceeding $10 \%$ as indicated in Table 1.

\section{Peak confirmation by UPLC/MS analysis}

Chromatograms obtained with UPLC/Fluorescence were very close for sterilized or non-sterilized samples, with only variations in BPA peak intensities depending on storage conditions. Therefore, only a few samples were chosen to be analyzed by UPLC/MS to ensure BPA confirmation (about 15\% of total number of sterilized samples were analyzed by UPLC/MS). The most intense ion for BPA is $[\mathrm{M}-\mathrm{H}]^{-}$at $\mathrm{m} / \mathrm{z}=$ 227.108. The confirmation was done with both $\mathrm{m} / \mathrm{z} \pm 0.01$ and retention time $\pm 0.05 \mathrm{~min}$ (Figure 1). Two other chromatographic peaks merged with the same $m / z$ (227.108), but at different retention times. Further investigation is required to identify the chemical structures corresponding to these peaks. The presence of other bisphenol analogues (such as BPF and BPS) was also examined; however, their presence could not be confirmed yet. 


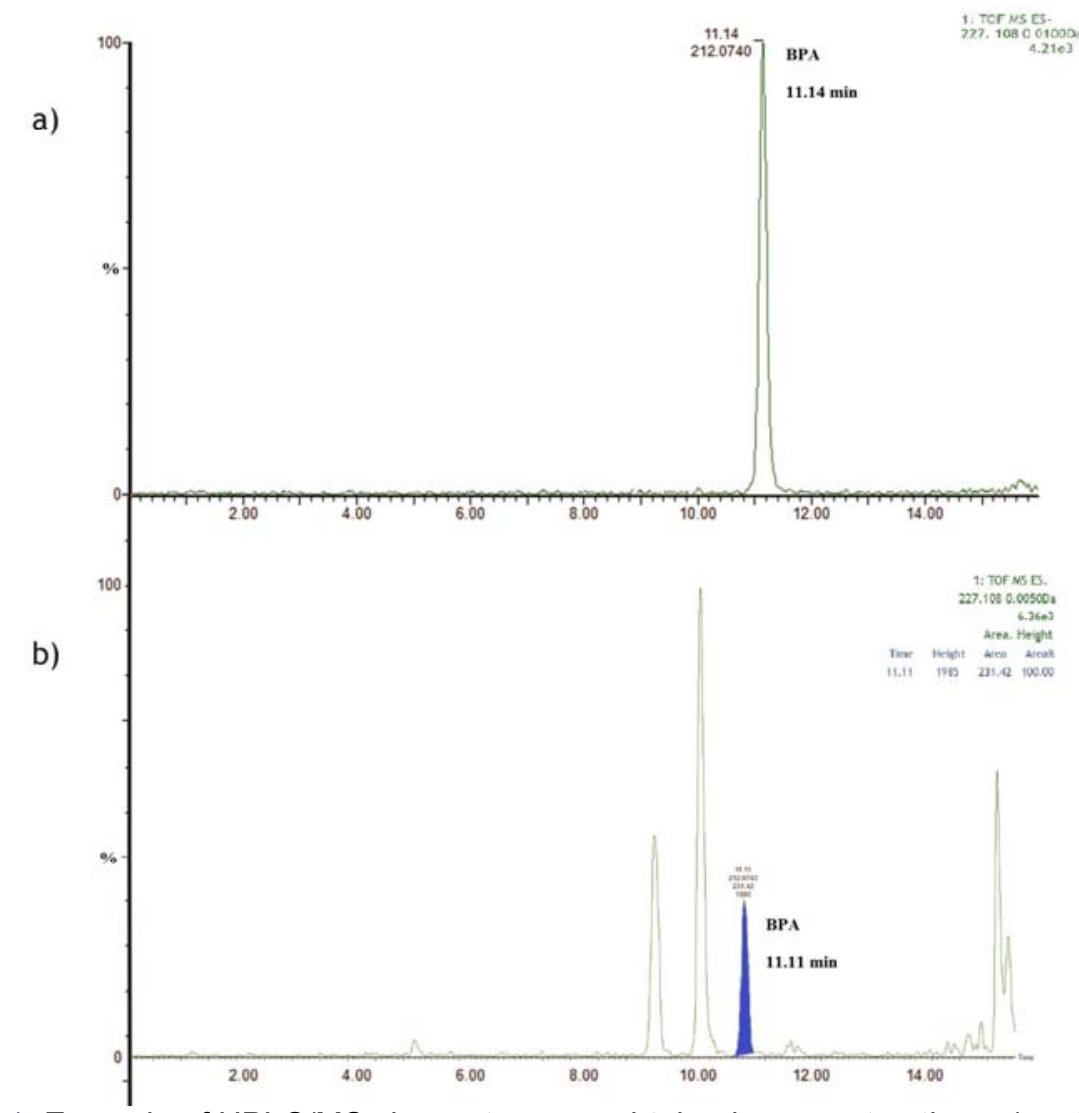

Figure 1. Example of UPLC/MS chromatograms obtained upon extracting $\mathrm{m} / \mathrm{z}=227.108$, characteristic of BPA. (a) BPA standard (100 $\mu \mathrm{g} / \mathrm{L})$; (b) BPA in simulant from (HP) can.

\section{Effect of heat processing}

All canned food is subjected to sterilization and it is well known that leaching of BPA is highly related to sterilization procedure. It is therefore interesting to study the coating resistance to sterilization and the level of BPA that can migrate before and after heat treatment. To our best knowledge only few studies considered the effect of sterilization of food cans on the migration of BPA (Cottier et al. 1998; Munguia-Lopez et al. 2001; Takao et al. 2002; Goodson et al. 2004; Cao et al. 2009a). In our work, (HP) and (NHP) cans stored at room temperature $\left(22.5^{\circ} \mathrm{C}\right)$ were analyzed at day 1 and day 15 . Results are presented in figure 2. BPA levels in aqueous simulant from (NHP) cans at day 1 were very low $(0.1-0.2 \mu \mathrm{g} / \mathrm{kg})$ whatever the type of cans; after 15 days of storage at room temperature, BPA concentrations increased significantly in aqueous simulant from (NHP) cans, reaching around $0.8 \mu \mathrm{g} / \mathrm{kg}$. Much higher levels of BPA were found in simulant from (HP) cans on day 1 (around $110 \mu \mathrm{g} / \mathrm{kg}$ ), but no significant change was noted after 15 days of storage. These results indicate that, even though free BPA monomer can migrate from the inner coating layer into the food stimulant in the case of non-sterilized cans stored under ambient temperature, heat processing is by far the most contributing factor on accelerating the migration of BPA. Most of free BPA monomer shall migrate into the canned food during the sterilization step, in agreement with data reported by other authors (Takao et al. 2002; Goodson et al. 2004; Sajiki et al. 2007). In particular, similar experiments using cans filled with water as an aqueous food simulant also showed a moderate BPA level increase in (NHP) cans (from $<0.2$ to $12.5 \pm 1.3$ $\mu \mathrm{g} / \mathrm{kg}$ ) after 160 days of storage, while after heat-processing migration of BPA 
remained constant around $80-90 \mu \mathrm{g} / \mathrm{kg}$ whatever the duration of storage $(0,40,70$ and 160 days) (Munguia-Lopez et al. 2001). Yet, the same authors obtained different results upon analyzing sterilized and non-sterilized canned fatty food simulant (sunflower oil), where most of the samples contained BPA below LOQ even in sterilized cans at $121^{\circ} \mathrm{C}$ for $50 \mathrm{~min}$ (Munguia-Lopez et al. 2005). This may be due to other contributing factors such as the nature of food simulant, the coating type (they tested samples packed in cans coated with both organosol and epoxy resins) and the sterilization conditions. Their results showed that sterilization of fatty food simulant for $50 \mathrm{~min}$ at $121^{\circ} \mathrm{C}$ caused much less BPA to migrate (most < LOQ) than cans autoclaved for $135 \mathrm{~min}$ at $111^{\circ} \mathrm{C}(54.3-$ $64.8 \mu \mathrm{g} / \mathrm{kg}$ ); therefore, it can be concluded that the sterilization time is more influencing than sterilization temperature (Munguia-Lopez et al. 2005). The same conclusion was reported for fatty-food simulant packed in epoxy-coated cans (Kang et al. 2003). Then, for a given sterilization time, migration is enhanced with elevated temperature as reported: BPA concentrations in empty cans heated for $30 \mathrm{~min}$ at $80^{\circ} \mathrm{C}$ were up to 6.1 times (average 3 times) less than in those heated $30 \mathrm{~min}$ at $100^{\circ} \mathrm{C}$ (Takao et al. 2002). So, the sterilization conditions do affect the level of BPA leaching into food although it's not very clear and requires further investigation to compromise between minimizing BPA leaching while still ensuring control of bacterial hazards.

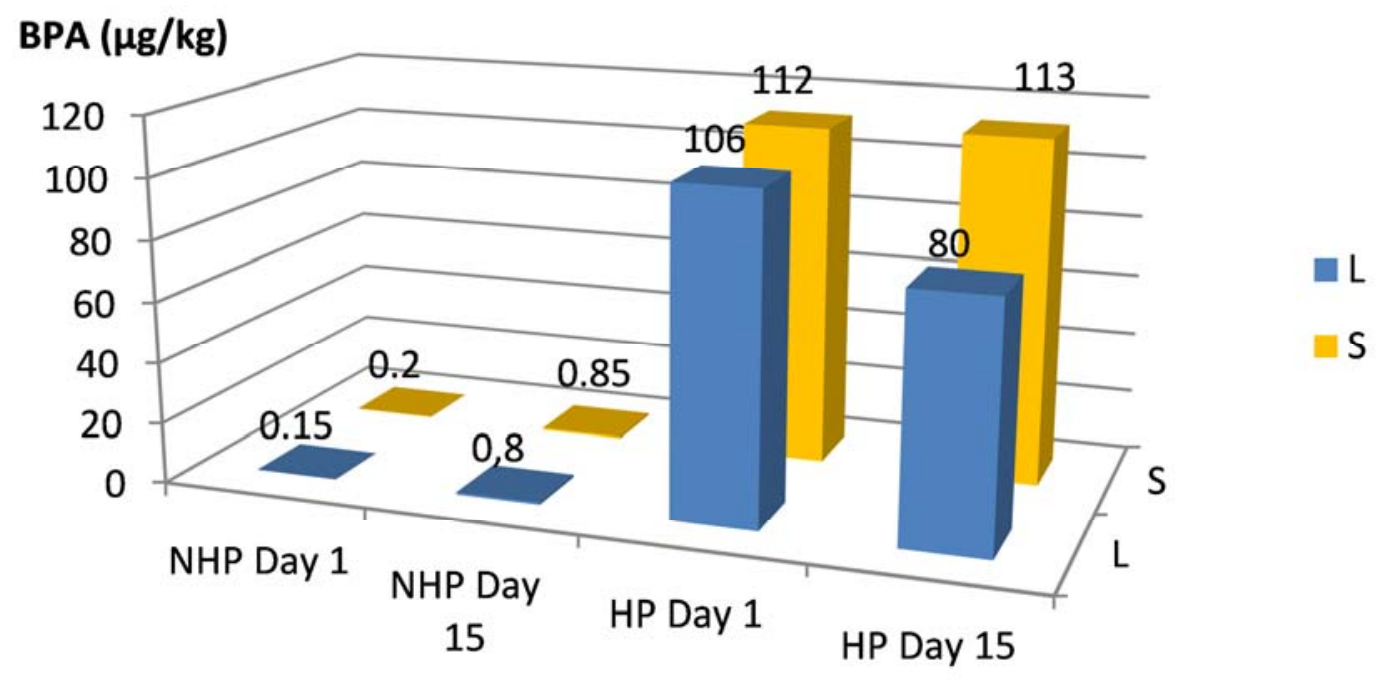

Figure 2. Migration level of BPA ( $\mu \mathrm{g} / \mathrm{kg}$ of food simulant) in large ( $\mathrm{L}$ ) and small $(\mathrm{S})$ cans either sterilised (HP) or non-sterilised (NHP) and stored at room temperature for 1 or 15 days.

In our study, the level of BPA in water simulant from sterilized cans ranged between 80 and $150 \mu \mathrm{g} / \mathrm{kg}$. These values are higher than the migration levels reported by most recent studies dealing with real foodstuff present in different countries (Grumetto et al. 2008; Cao et al. 2009b; Geens et al. 2010; Liao et al. 2014; Noonan et al. 2011), but still lower than the specific migration level $(600 \mu \mathrm{g} / \mathrm{kg})$ authorized by the European regulation (European Union 2011). They are also much lower than previous reported BPA levels (around $800 \mu \mathrm{g} / \mathrm{kg}$ ) in water simulant from tuna cans (Fasano et al. 2012).

\section{Effect of storage time and temperature}

Considerable amount of BPA migrated during sterilization, and the BPA levels found in sterilized cans showed only very small variations upon storage. The response surface of experimental design as well as the effect significance of storage time and temperature interaction is shown in figure 3 and Table 2, respectively. As the results show, there was no significant effect of storage temperature and time, neither their interaction ( $p$-value $>$ 
0.05), on the migration of BPA into aqueous food simulant. These results agree with previous work reporting $80-100 \%$ of free BPA present in the can coating to migrate into food during the sterilization stage (typically $90 \mathrm{~min}$ at $121^{\circ} \mathrm{C}$ ) (Goodson et al. 2004; Munguia-Lopez et al. 2005). Hence, for (HP) cans, storage time and temperature were found to have a minor effect on the migration of BPA into foodstuffs and food simulants, even with samples stored at $40^{\circ} \mathrm{C}$ for three months that simulates up to 3 years storage under ambient temperature (Goodson et al. 2004; Munguia-Lopez et al. 2005; Grumetto et al. 2008).

a)

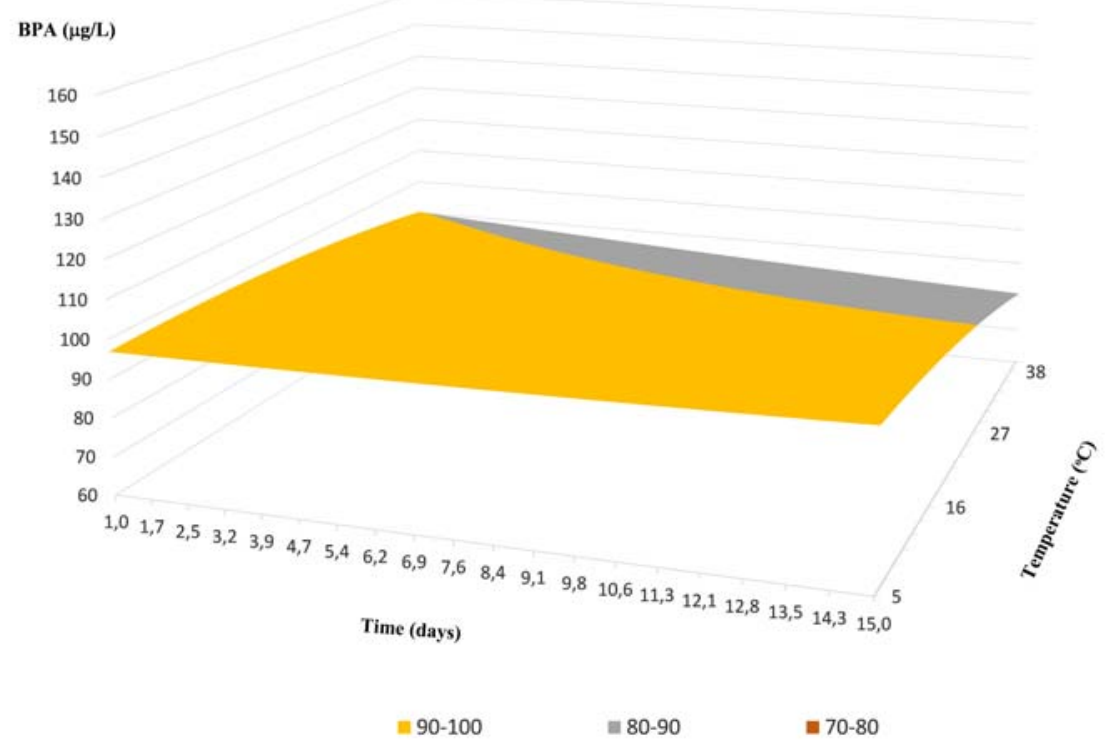

b)

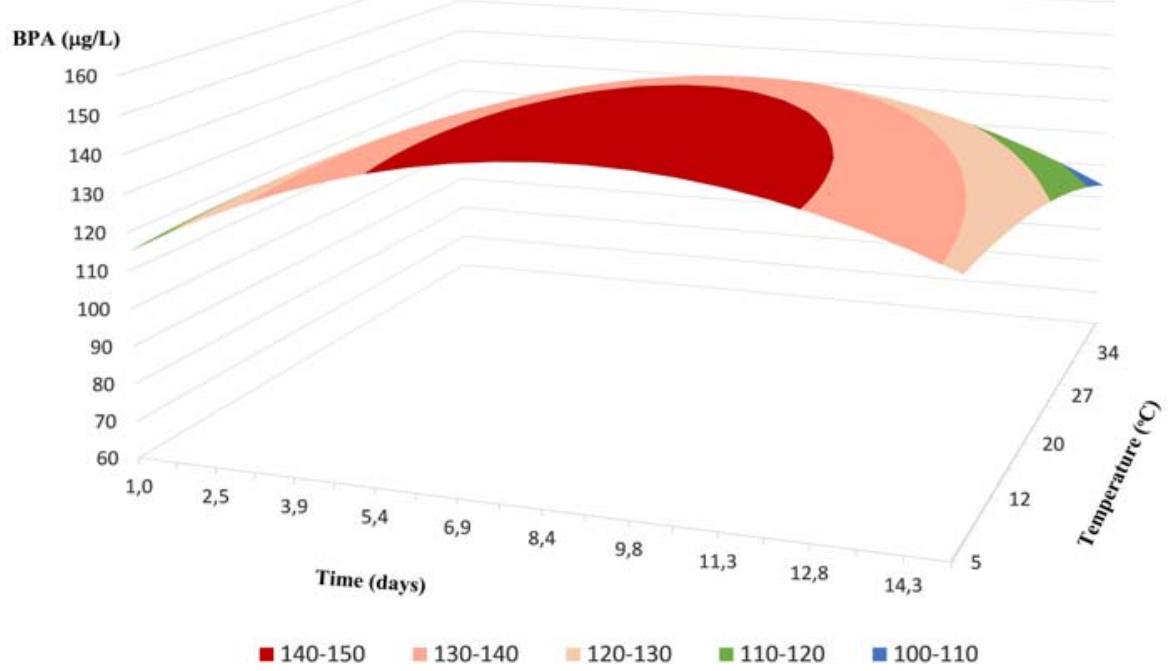

Figure 3. Surface plot of BPA migration level ( $\mu \mathrm{g} / \mathrm{kg}$ of food simulant) in sterilised cans as a function of storage time and temperature, (a) large (L) cans, (b) small (S) cans. 
Table 2. Response and effect significance of each experiment in the (JMP) experimental design for (HP) cans.

\begin{tabular}{ccccccc}
\hline Experiment & $\begin{array}{c}\text { Storage } \\
\text { temperature }\left({ }^{\circ} \mathrm{C}\right)\end{array}$ & $\begin{array}{c}\text { Storage time } \\
(\text { days })\end{array}$ & \multicolumn{2}{c}{ BPA concentration $(\mu \mathrm{g} / \mathrm{kg})$} & $\mathrm{p}-$ value $^{\mathrm{a}}$ \\
\cline { 5 - 6 } & & & $\begin{array}{c}\text { (L) type } \\
\text { cans }\end{array}$ & \\
\hline 1 & aa & -1 & -1 & 94 & 118 & \\
2 & $\mathrm{aA}$ & -1 & 1 & 108 & 133 & $>0.05$ \\
3 & $\mathrm{Aa}$ & 1 & -1 & 83 & 110 & $>0.05$ \\
4 & $\mathrm{AA}$ & 1 & 1 & 85 & 107 & $>0.05$ \\
5 & $\mathrm{a} 0$ & -1 & 0 & 92 & 138 & $>0.05$ \\
6 & $\mathrm{~A} 0$ & 1 & 0 & 88 & 126 & $>0.05$ \\
7 & $0 \mathrm{a}$ & 0 & -1 & 106 & 112 & $>0.05$ \\
8 & $0 \mathrm{~A}$ & 0 & 1 & 80 & 113 & $>0.05$ \\
9 & 0 & 0 & 0 & 84 & 134 & $>0.05$ \\
10 & 0 & 0 & 0 & 106 & 150 & $>0.05$ \\
\hline
\end{tabular}

${ }^{a}$ probability of significant effect at $95 \%$ confidence level $(\mathrm{p}<0.05)$

\section{Types of cans}

BPA migration may be affected by both the nature of the inner coating but also the geometry of the can. In our study, (L) and (S) cans differed in both aspects, since the former were coated with epoxy resin containing titanium oxide while the latter contained epoxy resin with carbon black and wax. As storage conditions had no effect on BPA levels in simulant for (HP) cans, we decided to consider these cans as two groups: all (L) and (S) type cans ( $\mathrm{n}=8$ per type of cans). A Student test clearly indicated ( $\mathrm{p}$-value $<0.0001)$ that BPA mean concentration in simulant from $(\mathrm{S})$ cans $(122.9 \mu \mathrm{g} / \mathrm{L})$ was significantly higher than in simulant from (L) cans $(92.3 \mu \mathrm{g} / \mathrm{L})$. Interestingly, taking into account the food surface contact area, there is no more evidence of difference between (L) and (S) cans since BPA migration is around $10.5 \mu \mathrm{g} / \mathrm{dm}^{2}$ for both types of cans. This value is in the same range as BPA migration data (around 8 $\left.\mu \mathrm{g} / \mathrm{dm}^{2}\right)$ recently reported for sterilized $\left(127^{\circ} \mathrm{C}, 24 \mathrm{~min}\right)$ epoxy-coated cans using also water as the aqueous simulant (Paseiro-Cerrato et al. 2017).

\section{Estimation of long term migration of BPA}

A few (NHP) and (HP) of (L) and (S) cans were stored at $60^{\circ} \mathrm{C}$ for 10 days. As mentioned in European Regulation 10/2011, this accelerated test shall mimic long term storage (above 6 months) at room temperature (or below) (European Union 2011). BPA concentration in simulant from (NHP) cans after 10 days increased from 0.1 to $45 \mu \mathrm{g} / \mathrm{kg}$ and from 0.2 to $23 \mu \mathrm{g} / \mathrm{kg}$, in (L) and (S) samples respectively (figure 4). On the other hand, the level of BPA in simulant from (HP) cans remained constant after 10 days in (L) cans (near $105 \mu \mathrm{g} / \mathrm{kg}$ ). Again this confirms the previous conclusion that migration of free BPA in the coating is enhanced during sterilization and that there is no further significant migration after storage in (HP) cans. Surprisingly, in sterilized (S) cans, the BPA level in aqueous simulant significantly decreased after 10 days at $60^{\circ} \mathrm{C}$. This unexpected result could possibly be attributed to BPA repartitioning in the coating under this temperature. As a matter of fact, microcrystalline wax (E 905) was used in the small cans to facilitate the meat sliding from the can, so that absorption of free BPA released in the simulant could have occurred in the wax over storage of (S) cans. 


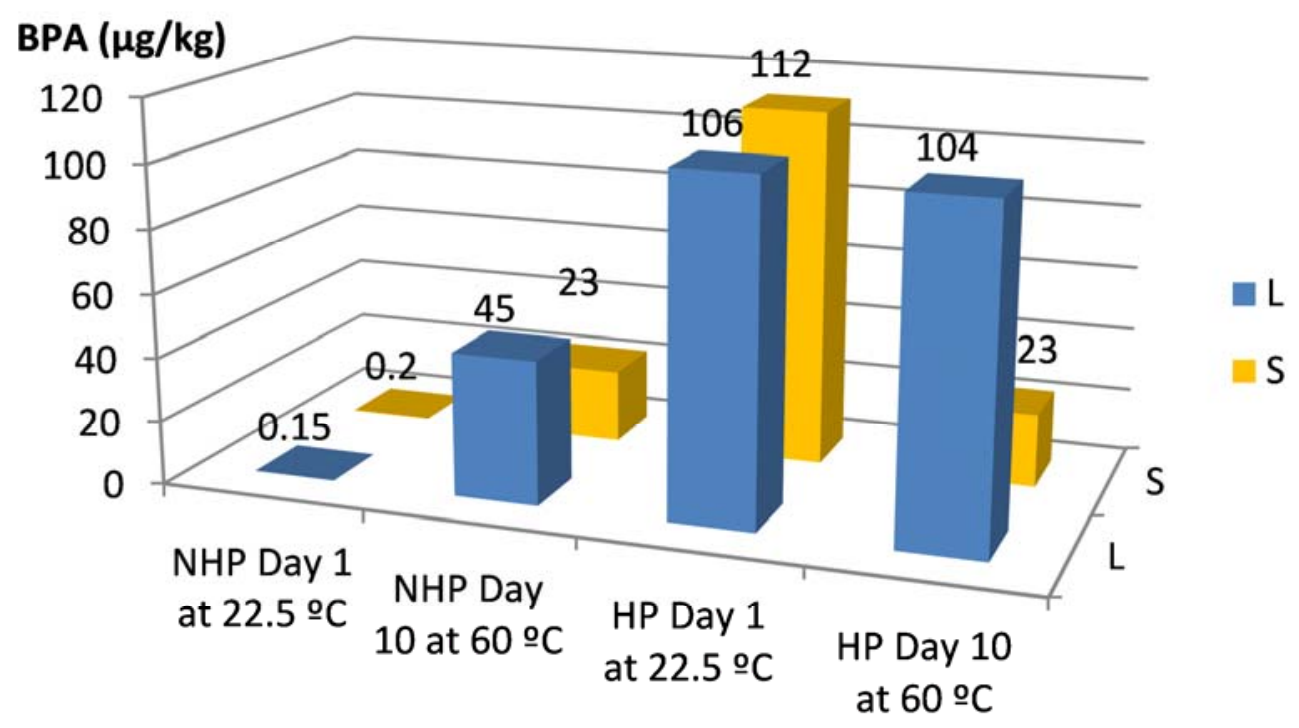

Figure 4. Difference in migration level of BPA ( $\mu \mathrm{g} / \mathrm{kg}$ of food simulant) in sterilised $(\mathrm{HP})$ and unsterilised (NHP) (L) and (S) cans, stored for 1 day at $22.5^{\circ} \mathrm{C}$ or 10 days at $60^{\circ} \mathrm{C}$.

\section{Conclusion}

Our results show that sterilization, at $121^{\circ} \mathrm{C}$ for $30 \mathrm{~min}$, greatly increases the release of BPA into aqueous food simulant. Nevertheless, the average migration levels reached (92 and $125 \mu \mathrm{g} / \mathrm{kg}$ in large and small cans respectively) were well below the EU regulation $(600 \mu \mathrm{g} / \mathrm{kg})$, which suggests that the BPA migration in Lebanese production of tinplate cans should be within the permitted limit. Interestingly, according to the computation done on JMP design of experiments software, there was no significant effect of short and long storage durations, under different temperatures, on sterilized cans. On the opposite, unsterilized cans were significantly affected by storage time and temperature, but BPA migration levels remained below those observed in sterilized cans. Hence, our results give clear evidence of the key role of the sterilization step on BPA migration level from tinplate cans. Consequently, the sterilization step should be carefully monitored in order to minimize the risk of releasing free monomers from the inner coating. Moreover, since our results show a constant level of BPA after sterilization, regardless of the storage duration and temperature, monitoring of cans varnishing could be helpful in minimizing, or even eliminating, these residual quantities of BPA free monomers. Finally, this study was based on aqueous food simulant and it is important to further investigate the migration of BPA into a wide variety of real canned food, where many other factors might affect the long term diffusion process, such as $\mathrm{pH}$ and amount of water or fat. At last, BPA is not the only compound susceptible to migrate from inner coating and related compounds (such as bisphenol A diglycidyl ether and its derivatives) should be investigated along with BPA to better understand migration mechanisms or competitions. 


\section{References}

Anses. 2015. Note d'appui scientifique et technique de l'Agence nationale de sécurité sanitaire de l'alimentation, de l'environnement et du travail relatif à la « Demande d'avis relatif à l'évaluation des risques pour la santé humaine du bisphénol A ».

Cao XL, Corriveau J, Popovic S. 2009a. Levels of Bisphenol A in Canned Soft Drink Products in Canadian Markets. J Agric Food Chem. 57(4):1307-1311.

Cao XL, Corriveau J, Popovic S, Clement G, Beraldin F, Dufresne G. 2009b.Bisphenol a in baby food products in glass jars with metal lids from Canadian markets. J Agric Food Chem.57(12):5345-5351.

Cottier S, Feigenbaum A, Montreuil P, Reynier A, Dole P, Riquet AM. 1998. Interaction of a vinylic organosol used as can coating with solvents and food simulants. J Agric Food Chem.46(12):5254-5261.

DTU Food. 2015. National Food Institute maintains its assessment of bisphenol A. http://www.food.dtu.dk

Efsa. 2015. Scientific Opinion on the risks to public health related to the presence of bisphenol A (BPA) in foodstuffs: Executive summary. EFSA J. 13(1): 3978.

Efsa. 2016. A statement on the developmental immunotoxicity of bisphenol A (BPA): answer to the question from the Dutch Ministry of Health, Welfare and Sport. EFSA J.14(10):4580.

European Union. 2011. COMMISSION REGULATION (EU) No 10/2011 of 14 January 2011 on plastic materials and articles intended to come into contact with food. Off J Eur Union.

Geens T, Apelbaum TZ, Goeyens L, Neels H, Covaci A. 2010. Intake of bisphenol A from canned beverages and foods on the Belgian market. Food Addit Contam Part A.27(11):1627-1637.

Goodson A, Robin H, Summerfield W, Cooper I. 2004. Migration of bisphenol A from can coatings--effects of damage, storage conditions and heating. Food Addit Contam.21(10):1015-1026.

Grumetto L, Montesano D, Seccia S, Albrizio S, Barbato F. 2008. Determination of Bisphenol A and Bisphenol B Residues in Canned Peeled Tomatoes by Reversed-Phase Liquid Chromatography. J Agric Food Chem.56(22):10633-10637.

Haffner D, Smith S, Harris TR, Paepke O, Birnbaum L. 2010. Bisphenol A (BPA) in U.S. Food. Environ Sci Technol.44(24):9425-9430.

Jalbani N, Kazi TG, Arain BM, Jamali MK, Afridi HI, Sarfraz RA. 2006. Application of factorial design in optimization of ultrasonic-assisted extraction of aluminum in juices and soft drinks. Talanta.70(2):307-314. 
Kang JH, Kito K, Kondo F. 2003. Factors influencing the migration of bisphenol A from cans. J Food Prot.66(8):1444-1447.

Lebanese Customs 2017. Trade Statistics.5 Years Comparative. Leban Cust. 20132016.http://www.customs.gov.lb.

Li D-K, Zhou Z, Miao M, He Y, Qing D, Wu T, Wang J, Weng X, Ferber J, Herrinton LJ, Zhu Q, Gao E, Yuan W. 2010. Relationship Between Urine Bisphenol-A Level and Declining Male Sexual Function. J Androl.31(5):500-506.

Liao C, Kannan K. 2014. A survey of bisphenol A and other bisphenol analogues in foodstuffs from nine cities in China. Food Addit Contam Part A.31(2):319-329.

Melzer D, Rice NE, Lewis C, Henley WE, Galloway TS. 2010. Association of urinary bisphenol A concentration with heart disease: Evidence from NHANES 2003/06. PLoS One. 5(1):8673.

Munguia-Lopez EM, Soto-Valdez H. 2001. Effect of Heat Processing and Storage Time on Migration of Bisphenol A (BPA) and Bisphenol A-Diglycidyl Ether (BADGE) to Aqueous Food Simulant from Mexican Can Coatings. J Agric Food Chem.49(8):36663671.

Munguia-Lopez EM, Gerardo-Lugo S, Peralta E, Bolumen S, Soto-Valdez H. 2005. Migration of bisphenol A (BPA) from can coatings into a fatty-food simulant and tuna fish. Food Addit Contam.22(9):892-898.

Noonan GO, Ackerman LK, Begley TH. 2011. Concentration of bisphenol a in highly consumed canned foods on the U.S. market. J Agric Food Chem.59(13):7178-7185.

Oldring PKT, Castle L, O’Mahony C, Dixon J. 2014. Estimates of dietary exposure to bisphenol A (BPA) from light metal packaging using food consumption and packaging usage data: a refined deterministic approach and a fully probabilistic (FACET) approach. Food Addit Contam Part A. 31(3):466-489.

République française. 2012. LOI n 2012-1442Visant à la suspension de la fabrication, de l'importation, de l'exportation et de la mise sur le marché de tout conditionnement à vocation alimentaire contenant du bisphénol A (Version consolidée au 1 mars 2017). Journal Officiel de la République française.

Rubin BS. 2011. Bisphenol A: An endocrine disruptor with widespread exposure and multiple effects. J Steroid Biochem Mol Biol. 127(1-2):27-34.

Sajiki J, Miyamoto F, Fukata H, Mori C, Yonekubo J, Hayakawa K. 2007. Bisphenol A (BPA) and its source in foods in Japanese markets. Food Addit Contam.24(1):103-112.

Takao Y, Lee HC, Kohra S, Arizono K. 2002. Release of Bisphenol A from Food Can Lining upon Heating. J Heal Sci.48(4):331-334. 